\title{
Well-structured teams and the buffering of hospital employees from stress
}

\author{
Sandra C Buttigieg* ${ }^{\star \dagger}$, Michael A West ${ }^{\ddagger}$ and Jeremy F Dawson ${ }^{\dagger}$ \\ *Department of Health Services Management, Faculty of Health Sciences, University of Malta, Msida, Malta; \\ †Work \& Organizational Psychology Group, Aston Business School, Aston University, Birmingham, UK; ${ }^{\ddagger}$ Department of \\ Organizational Psychology, Lancaster University Management School, Lancaster University, Lancaster, UK \\ E-mail: sandra.buttigieg@um.edu.mt
}

\begin{abstract}
Summary
Membership in well-structured teams, which show clarity in team and individual goals, meet regularly, and recognize diverse skills of their members, is known to reduce stress. This study examined how membership of well-structured teams was associated with lower levels of strain, when testing a work stressors-to-strains relationship model across the three levels of team structure, namely well-structured, poorly structured (do not fulfill all the criteria of well-structured teams) and no team. The work stressors tested, were quantitative overload and hostile environment, whereas strains were measured through job satisfaction and intention to leave job. This investigation was carried out on a random sample of 65,142 respondents in acute/specialist National Health Service hospitals across the UK. Using multivariate analysis of variance, statistically significant differences between means across the three groups of team structure, with mostly moderate effect sizes, were found for the study variables. Those in well-structured teams have the highest levels of job satisfaction and the least intention to leave job. Multigroup structural equation modelling confirmed the model's robustness across the three groups of team structure. Work stressors explained $45 \%, 50 \%$ and $65 \%$ of the variance of strains for well-structured, poorly structured and no team membership, respectively. An increase of one standard deviation in work stressors, resulted in an increase in $0.67,0.70$ and 0.81 standard deviations in strains for well-structured, poorly structured and no team membership, respectively. This investigation is an eye-opener for hospitals to work towards achieving well-structured teams, as this study shows weaker stressor-to-strain relationships for members of these teams.
\end{abstract}

\section{Introduction}

Stress researchers have long recognized that hospitals rate among the highest workplaces in terms of stress. ${ }^{1-4}$ Two work stressors, which have increasingly dominated the stress literature within hospital contexts, are quantitative overload $^{5,6}$ and hostility arising from staff, patients or relatives. $^{1,7-9}$ Exposure to work stressors leads to physical, psychological and behavioural strains. ${ }^{10-12}$ The consequences,

Dr Sandra C Buttigieg MD PhD FFPH, Senior Lecturer and Head of Department of Health Services Management, Faculty of Health Sciences, University of Malta, Msida, Malta; Visiting Research Fellow, Work \& Organizational Psychology Group, Aston Business School, Aston University, Birmingham, B4 7ET, UK.

Professor Michael A West BSc Econ (Hons) PhD, Professor of Organizational Psychology, Lancaster University Management School, Lancaster University, Lancaster LA1 4YX, UK.

Jeremy F Dawson BSc (Hons) MSc, RCUK Academic Fellow, Work \& Organizational Psychology Group, Aston Business School, Aston

University, Birmingham B4 7ET, UK. particularly in the health-care context, are wide ranging and far reaching, as one cannot expect health-care employees to perform optimally, unless they enjoy good physical and mental health. Quality of health-care delivery therefore depends on the strength and wellbeing of the human resource. Additionally, unwanted outcomes of work stress include human and economic costs. ${ }^{13}$ In the hospitals' demanding environment, where there is zero tolerance to error, researchers have endeavoured to identify evidence-based practices to improve the quality of the organizational environment that buffers health-care professionals from stressors, and at the same time ensures optimal patient care.

The practice of team working in health care has also gained considerable scholarly attention, and is acknowledged to result in reduced hospitalization and costs, improved service provision, reduced error rate, lower patient mortality and improved health, enhanced patient satisfaction, staff motivation and wellbeing, and innovations in patient care. ${ }^{14,15}$ However, several scholars argued that not all groups are teams, and that teams 
need to be well-structured for team effectiveness to be achieved. Membership of well-functioning teams is related with lower stress levels and better performance. ${ }^{15}$ Nevertheless, the progression of new knowledge on teamwork in relation to stress has been modest.

In this paper, we focused on the notion of team structure as buffering health employees from stress. This study aimed at investigating work stressor-to-strain relationships across three levels of team structure. The three levels included those that worked in well-structured teams; those that claimed worked in teams but did not fulfil all the criteria of well-structured teams and were referred to as working in poorly structured teams; and those that did not work in teams.

In this context, we chose to attempt to answer the following research questions:

(1) Were work stressors, namely quantitative overload and hostile environment associated with strains, namely job dissatisfaction and intention to leave job?

(2) Were there any differences in the study variables between those who worked in well-structured teams from those who worked in poorly structured teams and those who did not work in teams?

(3) To what extent was membership of well-structured teams associated with weaker work stressor-to-strain relationships in hospital practice?

Scholars in the field not only distinguished teams from groups, but went further to distinguish different types of teams. ${ }^{16,17}$ A group is a loose group of individuals, with low business impact and low team effectiveness. Individuals' skills and strengths do not combine with those of other group members, who are often effectively working alone. Hackman ${ }^{17}$ argued that first the collection of individuals working together must perceive themselves to be 'a real team' and that there are five enabling conditions that are necessary for teams to work effectively. These are the possession of 'a team task, clear boundaries, clearly specified authority to manage their own work processes and membership stability over some reasonable time'. ${ }^{17}$ Therefore, Hackman's conceptualization of a real team, deals with team structure. Others ${ }^{18}$ identified clear boundaries, interdependence and moderate stability of membership as three distinct features of well-structured teams. On the other hand, Anderson and West ${ }^{19}$ identified clarity of objectives, members' interdependence, regular meetings and a team size of less than 15, as the criteria for well-structured teams. Indeed, they are these criteria that have defined well-structured teams in this study. More recently, recognition of diverse skills and knowledge, as well as team-oriented tasks and context, were also identified as necessary for a collaborative approach. ${ }^{20}$ Well-structured teams are therefore more task-focused, with team members having complimentary skills, rather than competing with each other. The team-friendly structure allows them to address ongoing issues, address problems and achieve team tasks for the good of the organization. On the other hand, those members who claim they work in teams but do not fulfill all these criteria have been defined as being part of poorly structured teams. We propose that in poorly structured teams, tasks are superficially addressed, and the sum of the whole is less than the potential of the individual members. Indeed, poorly structured teams are more akin to loose groups or teams in the earlier stages of development.

A prominent study that examined the influence of teamwork in health care, was the one which examined 500 UK National Health Service (NHS) teams in primary health care, community mental health, acute hospitals and breast cancer care. ${ }^{15}$ This revealed strong evidence that working in well-structured and well-functioning teams was associated with higher quality and innovation of patient care, as well as with better staff wellbeing, and staff retention. Other studies linked team working in primary health care with lower hospitalization rates ${ }^{21}$ and in the case of operating theatres, with lower error rates. ${ }^{22}$ Research has consistently shown that work overload and hostile environment are associated with lower levels of job satisfaction and higher intentions to leave job. ${ }^{7,23,24}$ Therefore, based on these findings, we propose that wellstructured teams are expected to perceive lower levels of quantitative overload. Furthermore, the smooth functioning of well-structured teams enable their members to enjoy less hostility from colleagues, as well as from patients/relatives who may be more satisfied with the holistic care received. Staff members are therefore expected to be more satisfied in their job and less inclined to leave. A longitudinal national survey ${ }^{25}$ among general practitioners in England, found that job satisfaction was the main factor predicting intention to quit. Similar findings were found in nurses. ${ }^{26}$ Against this background, we propose the first hypothesis:

Hypothesis 1a: Those working in well-structured teams perceive lower levels of quantitative workload and hostility. On the other hand, they perceive higher levels of job satisfaction, and lower levels of intention to leave job.

Hypothesis 1b: Quantitative overload and hostile environment (external and internal hostility) are associated with staff job satisfaction, and intention to leave job.

Work stress has been defined in one of three ways: as a stimulus, response or a stimulus-response relationship. ${ }^{27}$ Stress as an independent variable - stimulus, which refers to job stressors, that is the physical or psychological stimuli to which individuals respond. ${ }^{10}$ In this study, the work stressors studied were quantitative workload and hostility. Stress as a dependent variable - response refers to strain, which is the physiological, psychological and/or behavioural deviation from an individual's healthy functioning in response to stressors. Job satisfaction and intention to leave job were the two measures of strain in this study. Finally stress as a stimulus-response relationship that takes into consideration the person-environment relationship. This is either a structural and quantitative interaction or a dynamic cognitive state - transaction. ${ }^{28,29}$ This study proposes that working in well-structured teams provides the right person-environment interaction that would buffer hospital employees from developing higher levels of strains. 
Hypothesis 2: The relationship between work stressors and strains for those working in well-structured teams is weaker, which is to say that an increase in work stressors would show a lower increase in strains for well-structured team membership, as opposed to poorly structured/no team membership.

\section{Methods}

\section{Description of sample}

The number of questionnaires in the acute/specialist hospitals amounted to 138,214 questionnaires in acute hospitals and specialist acute hospitals across the UK. The response rate was $53 \%$. Therefore, the number of respondents amounted to 65,142. As regards, the age profile, $28 \%$ and $30 \%$ lie in the $41-50$ and $31-40$ year age groups, respectively, whereas $81 \%$ are women and $19 \%$ are men. The occupational categories included management, all health-care professionals, administration, clerical and maintenance staff, with the highest being $28.4 \%$ registered nurses followed by $21.7 \%$ administration and clerical staff.

\section{Measures}

The items were taken from the UK NHS Staff Surveys (2004-2010) and for this investigation included measures for team structure, quantitative overload, hostility, job satisfaction and intention to leave job.

\section{Team structure}

Respondents were at the first instance asked 'Do you work in a team?" Those who answered "no" were labelled as being in no team, whereas those who answered "yes" were asked three further questions, which were regarded as criteria for well-structured teams, to which they had to give a yes/no answer. These questions were: 'Does your team have clear objectives?'; 'Do you have to work closely with other team members to achieve team objectives?' and 'Does the team meet regularly to discuss its effectiveness and how it could be improved?' Only those who answered yes to all three questions, as well as stating that they worked in teams of less than 15 members, were judged to be in well-structured teams. The rest who answered yes to the first question but no to one or more questions, or stating that they were in teams of more than 15 members, were labelled as being in poorly structured teams. Therefore, three groups were created: no teams, poorly structured teams and well-structured teams.

\section{Work stressors}

Work stressors were measured using five dimensions: three dimensions that form the construct quantitative overload, and two dimensions that form the construct hostile environment. Quantitative overload (QO) was measured using: (a) working extra hours for which respondents had to choose from seven options from 0 hours per week to more than 25 hours per week. (b) Social pressures to work extra hours, which was developed into a scale from six dichotomous (yes/no) items in response to statement 'I work more than my contracted hours...', namely '. . . because it is necessary to meet deadlines', 'because it is necessary to get ahead in my career', '. . . because it is expected by my manager', '. . . because it is expected by my colleagues', '. . . because it is impossible to do my job if I don't', and '....because I want to provide the best care I can for patients'. (c) Work pressure felt by staff, which had two 5 point Likert scale items, had a Cronbach's alpha of 0.77 and an inter-item correlation of 0.63 . Respondents indicated the extent to which they agreed or disagreed with 'I cannot meet all the conflicting demands on my time at work' and 'I do not have time to carry out all my work'.

Hostility (HO): External and internal hostility were developed into two separate scales from four dichotomous (yes/no) items, in response to the question 'In the past 12 months have you experienced physical violence and or harassment, bullying and abuse from any of the following?' For external hostility, the items referred to patients and relatives whereas for internal hostility, the items referred to manager/supervisor and colleagues. The interitem correlation between internal hostility and external hostility was 0.12 .

The underlying structure for work stressors was tested using split file analysis with exploratory factor analysis on the first half of the data identifying the two factors, namely quantitative overload and hostility. Confirmatory factor analysis (CFA) on the second half of the data, confirmed the underlying factor structure with good model fit indices, namely comparative fit index $(\mathrm{CFI})=0.96$, which is above $0.95,{ }^{30}$ and Tucker-Lewis Index (TLI) $=0.94$, which is above the recommended $0.90^{30}$ and RMSEA $=$ 0.041 , with $90 \%$ CI of 0.037 and 0.046 , which is below the recommended value of $0.08^{31}$ or less as indicating a reasonable error of approximation.

\section{Strains}

Work strains were measured using two dimensions, namely job satisfaction and intention to leave jobs. The construct job satisfaction (JS) is measured using four items and has a Cronbach's alpha of 0.87 and an inter-item correlation ranging from 0.4 to 0.6. In answering the question 'How satisfied are you with each of the following areas of your job?', respondents indicated the extent to which they were satisfied or dissatisfied to five-point Likert scale items, namely 'The support I get from my immediate manager', 'The freedom I have to choose my own method of working', 'The amount of responsibility I am given', and 'The extent to which my employer values my work'. The construct intention to leave jobs (Intlve) is measured using three items, with a Cronbach's alpha of 0.92 and an interitem correlation ranging from 0.7 to 0.8. In answering the question 'To what extent do you agree with the following?', respondents indicated the extent to which they agreed or disagreed to three five-point Likert scale items, namely 'I often think about leaving my 
current employer', 'I will probably look for a new job in the next year', and 'As soon as I can find another job, I will leave my current employer'.

Exploratory factor analysis using maximum likelihood, was carried out on half of the data using the nine items as measures of the theoretically derived construct strains. This clearly showed two factors: identified as job satisfaction and intention to leave jobs, with six and three manifest variables strongly loading on the two factors respectively. CFA on the second half of the data confirmed the underlying factor structure with good model fit indices, namely $\mathrm{CFI}=0.973$, TLI $=0.95$ and $\mathrm{RMSEA}=0.067$, with $90 \% \mathrm{CI}$ of 0.064 and 0.073 .

\section{Analysis}

The analysis was conducted in three stages to test the three hypotheses. SPSS 18 and AMOS 16.0 (analysis of moment

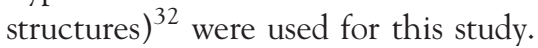

The first stage involved a one-way, between-groups multivariate analysis of variance, to investigate team structure differences in the study variables. Four dependent variables were used: quantitative overload, hostility, job satisfaction and staff intention to leave job. The independent variable was team structure: no team, poorly structured team and well-structured team. Preliminary assumption testing was conducted to check for normality, linearity and multi collinearity with no violation. The data were checked for univariate and multivariate outliers, which were eliminated. Because of the large sample size, equality of covariance matrices and equality of error variances were violated, such that a more conservative alpha level was needed to determine significance $(P<0.0001)$.

The second stage, used a multigroup structural equation-modelling design with cross-sectional samples of those who were perceived as working in well-structured teams $(n=21,201 ; 32.5 \%)$, those working in no team $(n=8013 ; 12.3 \%)$ and those in poorly structured teams $(n=25,988 ; 39.9 \%)$. In total, $9940(15.3 \%)$ did not respond to the items on team structure. Structural equation modelling was specifically chosen for this analysis because of its ability to manage complex models with observed and latent variables, measurement error, and multiple groups. Structural equation modelling has the ability to isolate measurement error, which is a ubiquitous threat to validity, by segregating reliable true variance from measurement error variance. Additionally, it was needed to test whether the hypothesized model fitted and was supported by empirical data. The models included several latent constructs. We consulted the literature on the controversial issue of using parcels as manifest variables in structural equation modelling. ${ }^{33}$ In this study, we chose the pragmatic-liberal philosophical perspective, in that parcels have potential merits as the lowest level of data to be modelled. For example, work stressors and strains were inserted in the path models, as latent constructs on the basis that different work stressors and psychological strains could be clustered. Through structural modelling, we could then estimate work stressor-to-strain relationships across the groups of team structure. The empirical justifications in favour of parcelling, were the distinct psychometric properties of the latent constructs, as well as the factor solution and model-fit characteristics achieved. Therefore, the models were more parsimonious, and had been checked for dual loadings, thereby resulting in a reduction of sampling error. ${ }^{34}$ The psychometric considerations were that work stressors and strains were more representative of the constructs intended to be measured in the conceptual framework, and that individual item scores were statistically less reliable than aggregate scores. ${ }^{33}$ The model-level consideration was that parcels could be used effectively to reduce the number of indicators to an optimal, just-identified level, thereby reducing type 1 error. ${ }^{33}$

In line with Byrne's recommendations, ${ }^{35}$ on seeking evidence of multigroup invariance in factorial and proposed structure, several questions needed to be considered, namely:

(1) Was the factorial structure of the conceptual framework equivalent across teams?

(2) Were the paths in the proposed structure invariant across team structure?

(3) Were the latent means of the constructs different across team structure?

The estimation of the baseline models did not involve between-group constraints and therefore could be analysed separately for each group. ${ }^{35}$ However to test for invariance, equality constraints needed to be imposed. The data for all groups had to be analysed simultaneously to obtain efficient estimates. ${ }^{36}$ The testing for invariance started with a global test of the equality of covariance structures across groups. In line with the null hypothesis of non-equivalence of groups, if the null hypothesis was rejected, then one could proceed with subsequent testing of increasingly restrictive hypotheses, so as to identify the source of non-invariance. ${ }^{35}$

\section{Results}

In this section, we will provide the results and systematically address the hypotheses and whether they were supported.

\section{Descriptive statistics}

\section{Team structure}

There were no meaningful differences in terms of proportions between those in well-structured teams versus those in no team and in poorly structured teams when comparing the three groups by age, gender, ethnic background, disability, job tenure or work-time contract. With regard to occupational groups, general managers are the most likely to work in well-structured teams $(62 \%)$, whereas the least likely are the maintenance staff (23\%). All other groups ranged between 35\% and 48\%.

Table 1 shows the means, standard deviations, and differences between means and correlations between variables in the model, across the three groups of team 


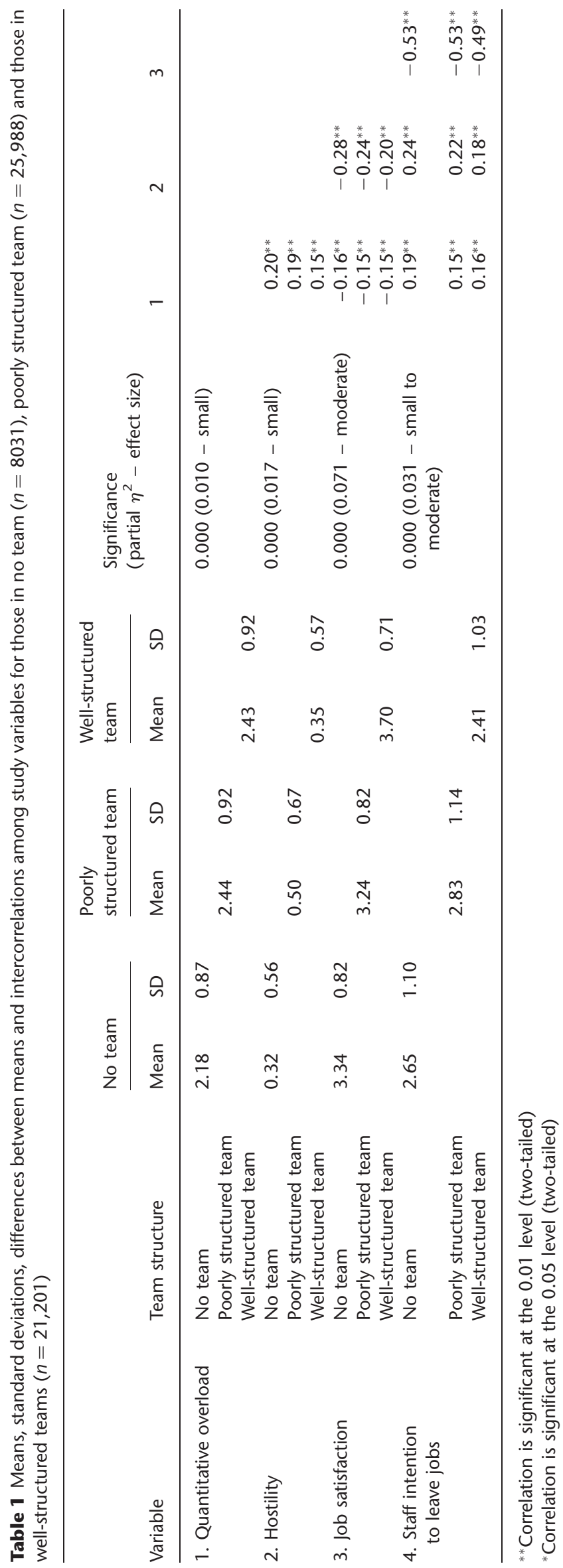

structure. Most of the study variables are moderately correlated. The set of multivariate tests of significance, namely Wilk's lambda (0.857) and Pillai's trace (0.146) with significance value of $P<0.0001$, show statistically significant differences between those in well-structured teams, poorly structured team and no team.

The results showed statistically significant differences across all variables. Those in well-structured teams had higher means for quantitative overload than those in no team and similar to those in poorly structured teams. This was not as proposed in hypothesis 1a, namely that wellstructured teams have lower levels of quantitative overload. This might be due to the notion of teams expected to have the total outcome greater than the sum of individual outcome, as well as due to the expectation that the work was efficiently and effectively shared among team members, thereby succeeding in processing more work. On the other hand, those in well-structured teams perceived lower means of hostility and this was in accordance with hypothesis $1 \mathrm{a}$. Furthermore, those in well-structured teams showed higher means for job satisfaction, and lower means for staff intention to leave job, as opposed to poorly structured/no team. This result also supported hypothesis 1a. As $P$ values could not provide the strength of association between variables, in particular because of the large samples, since even very small differences could become statistically significant. Therefore, the strength of the association or the effect size was calculated using $\eta^{2}$. The strength varied from small to more than moderate effect. This supported hypotheses $1 \mathrm{a}$ and $1 \mathrm{~b}$. An interesting finding was that those members of poorly structured teams had lower levels of job satisfaction, and higher levels of hostility and intention to leave job than those that did not work in a team at all.

Furthermore, the correlation matrix showed that quantitative overload was negatively correlated with job satisfaction $(r=0.15-0.20 ; \quad P<0.001)$ and positively correlated with intention to leave job $(r=0.15-0.19$; $P<0.001$ ). Additionally, hostility was negatively correlated with job satisfaction $(r=0.20-0.28 ; P<0.001)$ and positively correlated with intention to leave job $(r=0.18-0.24 ; P<0.001)$. These results supported hypothesis $1 \mathrm{~b}$ both in terms of their association, as well as direction.

For the second stage of the analysis, the proposed structural equation model (Figure 1) was specified with its measurement and structural coefficients constrained to equality to test its structural invariance across team structure. Specifically, the direction of the paths was specified to be equal across team structure. The part of the model that was analysed was the proposed link between work stressors and strains.

The hypothesized model was tested against four-factor structure measurement models (QO, HO, JS and Intlve); and a null-factor model (the data did not yield a single factor). The improvement of model fit was tested by calculating the differences in $\chi^{2}$ values to degrees of freedom $\left(\chi^{2} / \mathrm{d} f\right)$ for each model (Table 2$)$.

The test indicated a significant model improvement for the proposed model over the null model and the 


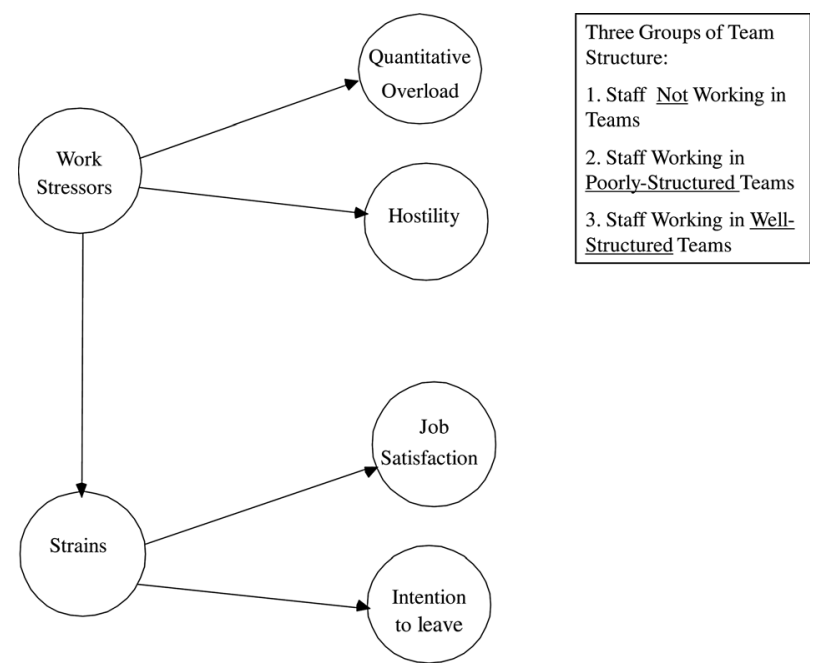

Figure 1 Conceptual model of work stressor-to-strain relationship tested simultaneously across three groups of team structure

perfectly correlated four-factor structure (Table 2), suggesting that the proposed model fitted the data better. As expected, the correlated measurement model fitted the data best. The data were tested for multivariate normality. Mardia's measure of multivariate normality based on skewness and kurtosis is $40.35(P<0.05)$, which meant significant non-normality. However, considering the large sample sizes in this study, violation of normality assumption was expected. However, maximum likelihood was used, as this is robust with large sample sizes. ${ }^{37}$ Hypothesis 1b, namely that quantitative overload and hostile environment (external and internal hostility) were associated with staff job satisfaction and intention to leave jobs, was further supported. Evidence converged in support of the proposed model and its robustness across team structure. Work stressors significantly influenced strains. Furthermore, the direction, strength and significance of all parameter estimates were consistent with theory and across team structure.

The good fit statistics for the baseline models (Table 3) did not guarantee equivalence of underlying theoretical structure across the three groups of team structure. Therefore we tested the model with the three groups simultaneously.
Table 3 Model fit statistics of the baseline models (work stressors-to-strains relationship) of the three models

\begin{tabular}{lcccc}
\hline & CFI & TLI $\rho^{2}$ & RMSEA $($ LO 90, HI 90) & $\chi^{2} / \mathrm{df}$ \\
\hline All respondents & 0.95 & 0.92 & $0.064(0.064,0.065)$ & 272.0 \\
No team & 0.95 & 0.92 & $0.065(0.063,0.068)$ & 35.23 \\
$\begin{array}{l}\text { Poorly structured } \\
\quad \text { team }\end{array}$ & 0.94 & 0.92 & $0.064(0.063,0.066)$ & 108.34 \\
$\begin{array}{l}\text { Well-structured } \\
\quad \text { team }\end{array}$ & 0.94 & 0.91 & $0.064(0.062,0.065)$ & 87.30 \\
& & & & \\
\hline
\end{tabular}

CFI, comparative fit index; TLI, Tucker Lewis index; RMSEA, root mean square error of approximation; df, degrees of freedom

Table 4 shows the models' total effects, standardized effects and squared multiple correlations, with noticeable differences between the three groups. The squared multiple correlations for strains were 0.45 (well-structured team), 0.50 (poorly structured team) and 0.65 (no team).

This meant that work stressors explained $45 \%, 50 \%$ and $65 \%$ of the variance of strains for well-structured, poorly structured and no team membership. The standardized estimates for the unconstrained models of the three groups were 0.81 for no team; 0.70 for poorly structured team; and 0.67 for well-structured teams. This meant that when stressors went up by one standard deviation, strains went up by 0.81 (no team), 0.70 (poorly structured team) and 0.67 (well-structured team) standard deviations, respectively. These findings supported hypothesis 2, namely that the relationship between work stressors and strains for those working in well-structured teams was weaker. Table 5 shows the goodness-of-fit statistics for tests of invariance across different groups of team structures.

The results in Table 5, showed the conceptual framework's robustness across team structure. However, the comparison between the unconstrained and constrained models showed statistically significant $\chi^{2}$ difference tests. Therefore, provided with this information, one could conclude that the equality constraints, except for the stressorstrain path between no team and poorly structured team groups, did not hold across the three groups of team structure, such that there were differences between those that work in well-structured teams from those that did not.

Table 2 Model fit indices of the model (work stressors-to-strains) for all respondents, over the four-factor measurement model

\begin{tabular}{|c|c|c|c|c|c|c|}
\hline & $x^{2}$ & $d f$ & $\mathrm{CFI}$ & TLI $\rho^{2}$ & RMSEA (LO 90, HI 90) & $\chi^{2} / \mathrm{df}$ \\
\hline Null model & 260648.79 & 78 & & & $0.226(0.226,0.227)$ & 3341.65 \\
\hline Four-factor measurement model (perfectly correlated)* & 93110.15 & 54 & 0.64 & 0.49 & $0.163(0.162,0.164)$ & 1724.26 \\
\hline Four-factor measurement model (correlated) ${ }^{\dagger}$ & 10760.60 & 48 & 0.96 & 0.93 & $0.059(0.058,0.059)$ & 224.18 \\
\hline Proposed model ${ }^{\ddagger}$ & 14141.60 & 52 & 0.95 & 0.92 & $0.064(0.064,0.065)$ & 271.95 \\
\hline
\end{tabular}

$N=65,142 ; \mathrm{CFI}$, comparative fit index; TLI, Tucker Lewis index; RMSEA, root mean square error of approximation; df, degrees of freedom $*$ Difference four-factor (perfectly correlated) and null model: $\Delta \chi^{2}(\mathrm{df})=167538.64(24)^{* * *}$

${ }^{\dagger}$ Difference four-factor (correlated) and four-factor (perfectly correlated) model: $\Delta \chi^{2}$ (df) $=823945.55(8)^{* * * *}$

${ }^{*}$ Difference four-factor (correlated) and proposed model: $\Delta \chi^{2}(\mathrm{df})=3381(4)^{* * * *}$

Difference four-factor (perfectly correlated) and proposed model: $\Delta \chi^{2}(\mathrm{df})=789868.55(2)^{* * *}$

***P $<0.001$ 
Table 4 Total effects, standardized total effects and squared multiple correlations

\begin{tabular}{|c|c|c|c|c|c|c|}
\hline & Samples & $\begin{array}{l}\text { Quantitative } \\
\text { overload }\end{array}$ & Hostility & $\begin{array}{l}\text { Job } \\
\text { satisfaction }\end{array}$ & $\begin{array}{l}\text { Staff intention } \\
\text { to leave job }\end{array}$ & Strains \\
\hline \multirow[t]{3}{*}{ Total effects } & No team & 1.00 & 0.85 & -1.36 & 1.84 & 1.51 \\
\hline & Poorly structured team & 1.00 & 0.96 & -1.05 & 1.48 & 1.16 \\
\hline & Well-structured team & 1.00 & 0.83 & -0.91 & 1.59 & 0.83 \\
\hline \multirow[t]{3}{*}{ Standardized total effects } & No team & 0.56 & 0.50 & -0.60 & 0.67 & 0.81 \\
\hline & Poorly structured team & 0.60 & 0.59 & -0.52 & 0.59 & 0.70 \\
\hline & Well-structured team & 0.59 & 0.52 & -0.48 & 0.58 & 0.67 \\
\hline \multirow[t]{3}{*}{ Squared multiple correlations } & No team & 0.31 & 0.25 & 0.58 & 0.71 & 0.65 \\
\hline & Poorly structured team & 0.36 & 0.35 & 0.57 & 0.72 & 0.50 \\
\hline & Well-structured team & 0.35 & 0.27 & 0.50 & 0.75 & 0.45 \\
\hline
\end{tabular}

Goodness-of-fit measures showed that this association occurred across the three groups of team structure; however there was factorial and structural non-equivalence across the three groups. There was structural invariance in the work-stressor-strain path between those in no team and those in poorly structured team.

\section{Discussion}

This study investigated a proposed work stressor-to-strain relationships model across three levels of team structure. Using multivariate analysis of variance, statistically significant differences between means across the three groups of team structure, with mostly moderate effect sizes, were found for the study variables. Those in well-structured teams perceived higher levels of overload, but lower levels of hostility. They had the highest levels of job satisfaction and the least intention to leave job. With the exception of the finding on quantitative overload, all the other findings were in agreement with theory as pronounced in the literature and with previous evidence on well-functioning teams, ${ }^{15}$ which could be considered as similar to teams in the performing stage. ${ }^{38}$

Through structural equation modelling, the models, which depicted the hypothesized relationships, achieved good model fit statistics across team structure. Work stressors explained $51 \%$ of the variance of strains for all respondents and $45 \%, 50 \%$ and $65 \%$ of the variance of strains for well-structured, poorly structured and no team membership, respectively. Using multigroup structural equation modelling, the results confirmed the model's robustness across the three groups of team structure. However, factorial and structural non-equivalence between the three groups confirmed that differences did exist between the groups. The exception was the structural invariance in the work stressors-strains path between those on no team and those in poorly structured team.

The finding that those members of poorly structured teams had lower levels of job satisfaction, and higher levels of hostility and intention to leave job than those that did not work in a team at all, might be explained in terms of poorly structured teams that might well be compared with the stage of storming of team development, ${ }^{38}$ in which uncertainties, lack of consensus on decision- making and conflict prevail. These factors might have contributed to the staff members' frustrations as shown in terms of higher levels of strains that their teams were not well-structured, and therefore were not achieving the expectations in line with their personal goals as team members.

This study has several limitations. First of all, this study was limited on the choice of using specific variables for work stressors and strains. Indeed, apart from quantitative overload, hostility, job satisfaction and intention to leave job, there might be other constructs that could be studied as representing stressors and strains. Secondly, the cross-sectional nature of the data does not allow drawing any conclusions in terms of causality. It would be worth examining longitudinal data collected as part of the NHS staff surveys. Thirdly, the use of self-report data highlights the problem of percept-percept bias, ${ }^{39}$ which is specifically associated with single source data collection. Several studies have attempted to evaluate the extent to which common method variance inflates the relationships among constructs. While self-report methodology still provides meaningful relationships, ${ }^{40}$ common method variance does in fact result in percept-percept. ${ }^{41}$ Midway between these apparently paradoxical conclusions, this bias is domain specific and identified job satisfaction, turnover intentions and role characteristics as being among those particularly susceptible to inflationary effects. ${ }^{39}$ Unfortunately, these were among the perceptual measures that were collected from the same employees when completing the same survey, at one point in time. Without objective measures, participants could have provided inaccurate or socially acceptable responses. However, there were several steps that were utilized to alleviate the problem. ${ }^{42}$ The questionnaires were completed in privacy and full confidentiality was ensured, thereby reducing the motive to answer favourably in a manner to please the employer. Furthermore, the questionnaire had a variety of response scales or anchors, which is a useful tactic to minimize bias. ${ }^{41}$

The strength of this study lay in the large sample size of 65,142 respondents in acute/specialist British NHS hospitals. However, the downside to this was that with such a sample size, nearly all relationships tested, achieved statistical significance, with the conclusion that the $P$ value 


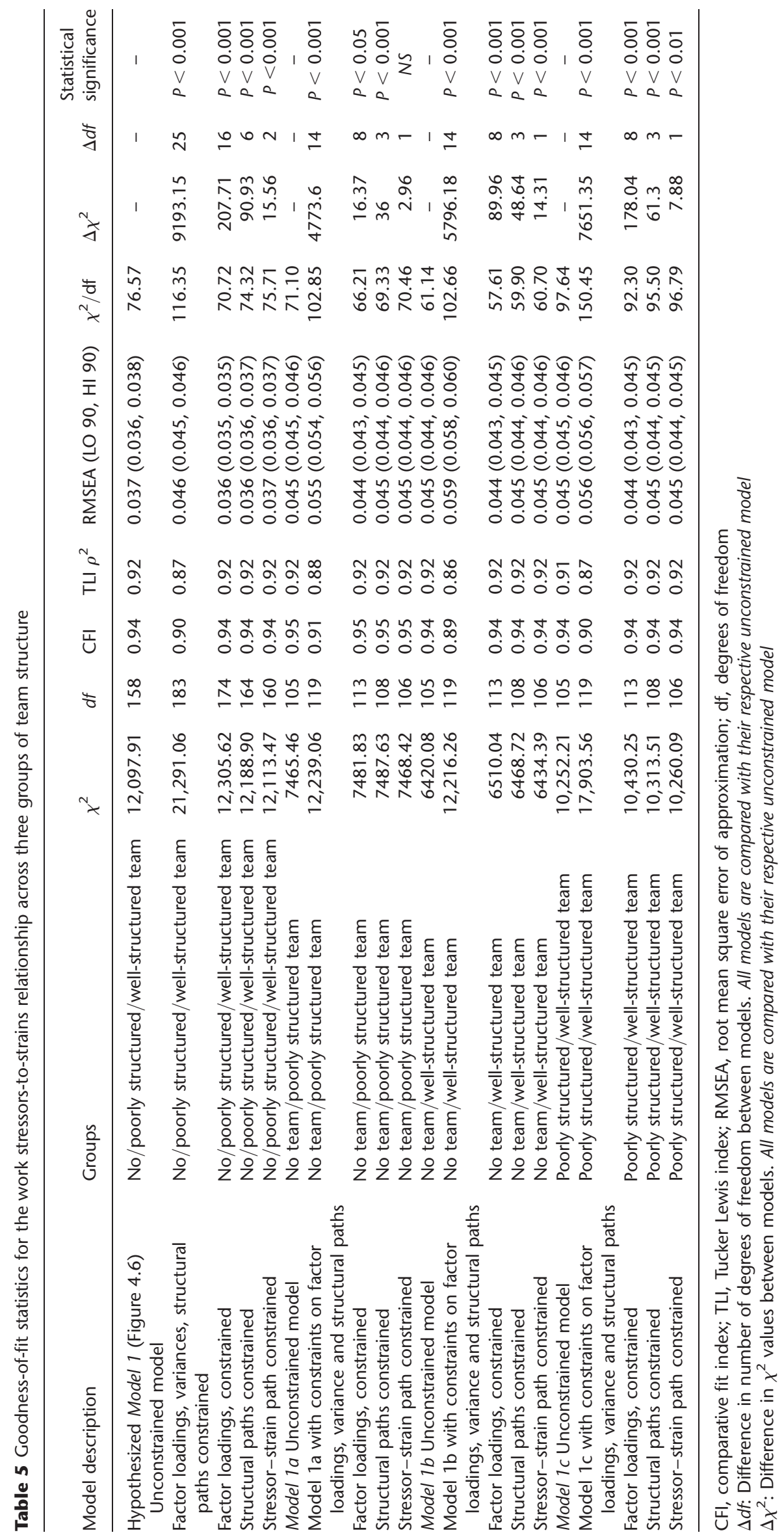


had minimal value. For this reason, we worked out effect sizes to gauge the magnitude of the relationships.

Finally, the use of latent constructs in this study was warranted as our goal was to model the effects of work stressors and strains at a level of generality, so that with the appropriate parcelling of items, we could minimize the effects of nuisance factors at a lower level of generality.

\section{Conclusion}

This study provided several results with theoretical, methodological and practical implications. The theoretical expectation that well-structured teams had a weaker stressors-to-strains relationship, was confirmed by the sample data. Although the stressor-strain link has been studied before, the theoretical contribution of this study was in presenting this link across different team structures. The methodological contribution was in the use of multigroup structural equation modelling to investigate the stressors-to-strains relationship across the three types of team structure. The advantages of using multigroup structural equation modelling were the ability to model error terms and the ability to test models across multiple groups by testing primarily for model robustness across groups with the added flexibility of assessing relative model fit between the groups.

The finding of statistically significant differences between the three groups of team structure, provided practical implications for work practices in acute/specialist hospitals. The results showed that those working in wellstructured teams had the highest levels of job satisfaction and the least intention to leave job. Finally, those in poorly structured teams had the highest intention to leave job and the lowest job satisfaction from the three groups. This was a revelation for team-friendly organizations to work towards achieving well-structured teams, rather than be content with any team, as poorly structured team members seemed to fare worse than those working in no team.

\section{References}

1 Cox T, Griffiths A, Cox S. Work-Related Stress in Nursing: Controlling the Risk to Health. Geneva: Conditions of Work and Welfare Facilities Branch, International Labour Office, 1996

2 Firth-Cozens J. Editorial - Doctors, their wellbeing, and their stress. BMJ 2003;326:670-6

3 Gibb J, Cameron IM, Hamilton R, Murphy E, Naji S. Mental health nurses' and allied health professionals' perceptions of the role of the Occupational Health Service in the management of work-related stress: how do they self-care? J Psychiatr Ment Health Nurs 2010;17:838-45

4 Siegrist J, Shackelton R, Link C, Marceau L, von dem Knesebeck O, McKinlay J. Work stress of primary care physicians in the US, UK and German health care systems. Soc Sci Med 2010;71:298-304

5 Greenglass ER, Burke RJ, Moore KA. Reactions to increased workload: effects on professional efficacy of nurses. Appl Psychol Int Rev 2003;52:580-97

6 Hauck EL, Snyder LA. Workload variability and social support: effects on stress and performance. Curr Psychol 2008;27:112-25
7 Di Martino V. Relationship of Work Stress and Workplace Violence in the Health Sector. Geneva: International Labour Office ILO International Council of Nurses ICN, World Health Organisation WHO Public Services International PSI, 2003

8 Jackson D, Clare J, Mannix J. Who would want to be a nurse? Violence in the workplace - a factor in recruitment and retention. J Nurs Manag 2002;10:13-20

9 Jones TL, Argentino D. Nurse-to-nurse hostility, confrontational anxiety, and emotional intelligence: an integral, descriptive pilot study. J Perianesth Nurs 2010;25:233-41

10 Cooper CL, Quick JC. Stress and Strain. Oxford: Health Press Ltd, 1999

11 Trenberth L, Dewe P. Understanding the experience of stressors: the use of sequential analysis for exploring the patterns between various work stressors and strain. Work Stress 2006;20:191-209

12 van Dick R, Wagner U. Stress and strain in teaching: a structural equation approach. Br J Educ Psychol 2001;71:243-59

13 Dollard MF, Winefield HR, Winefield AH, de Jonge J. Psychosocial job strain and productivity in human service workers: a test of the demand-control-support model. J Occup Organ Psychol 2000;73:501-11

14 West MA, Borrill CS, Unsworth KL. Team effectiveness in organizations. In: Cooper CL, Roberstson IT eds. International Review of Industrial and Organizational Psychology. Vol 13. Chichester: John Wiley \& Sons, 1998: 1-48

15 Borrill C, Carletta J, Carter AJ, et al. The Effectiveness of Health Care Teams in the National Helath Service. London, UK: Aston University, University of Glasgow, University of Leeds, 2002

16 Katzenbach JR, Smith DK. The Wisdom of Teams. Berkshire: McGraw-Hill, 1998

17 Hackman RJ. Leading Teams: Setting the Stage for Great Performances. Boston: Harvard Business School Press, 2002

18 Wageman R, Hackman JR, Lehman E. Team diagnostic survey: development of an instrument. J Appl Behav Sci 2005;41:373-98

19 Anderson NR, West MA. Measuring climate for work group innovation: development and validation of the Team Climate Inventory. J Organ Behav 1998;19:235-58

20 So T, West MA, Dawson JF. Team-based working and employee well being: A cross-cultural comparison of United Kingdom and Hong Kong health services. Eur J Work Eु Organ Psychol 2011;20:305-25

21 Sommers L, Marton K, Barbaccia J, Randolph J. Physician, nurse and social worker collaboration in primary care for chronically ill seniors. Arch Intern Med 2000;160:1825-33

22 Sexton BJ, Thomas EJ, Helmreich RL. Error, stress, and teamwork in medicine and aviation: cross sectional surveys. BMJ 2000;320: $\underline{745-9}$

23 Hetlevik O, Hunskar S. The length of the patient list, waiting lists, workload and job satisfaction among general practitioners in Bergen. Tidsskr Nor Laegeforen 2004;124:813-5

24 Kaarna M, Pólluste K, Lepnurm R, Thetloff M. The progress of reforms: job satisfaction in a typical hospital in Estonia. Int J Qual Health Care 2004;16:253-61

25 Sibbald B, Bojke C, Gravelle H. National survey of job satisfaction and retirement intentions among general practitioners in England. BMJ 2003;326:22-4

26 Murrells T, Clinton M, Robinson S. Job satisfaction in nursing: validation of a new instrument for the UK. J Nurs Manag 2005; 13:296-311

27 Jex SM, Beehr TA, Roberts CK. The meaning of occupational stress items to survey respondents. J Appl Psychol 1992;77:623-8

28 Dollard MF, Winefield HR, Winefield AH, de Jonge J. Psychosocial job strain and productivity in human service workers: a test of the demand-control-support model. J Occup Organ Psychol 2000;73: $501-11$

29 Lazarus RS, Folkman S. Stress, Appraisal and Coping. New York: Springer, 1984 
30 Bentler PM. EQS: Structural Equations Program Manual. Encino, CA: Multivariate Software Inc, 1995

31 Browne MW, Cudeck R. Alternative ways of assessing model fit. In: Bollen KA, Long JS, eds. Testing Structural Equation Models. Newbury Park, CA: Sage, 1993: 136-62

32 Arbuckle JL. AMOS 16.0 User's Guide. Chicago: Small Waters Corporation, 2009

33 Little TD, Cunningham WA, Shahar G, Widaman KF. To parcel or not to parcel: exploring the questions, weighing the merits. Struct Eq Model 2002;9:151-73

34 MacCallum RC, Widaman KF, Zhang S, Hong S. Sample size in factor analysis: the role of medical error. Multivariate Behav Res 2001;4:611-37

35 Byrne BM. Structural Equation Modeling with AMOS. New Jersey: Lawrence Erlbaum Associates, Publishers, 2001

36 Joreskog KG, Sorbom D. LISREL 8: User's Reference Guide. Chicago: Scientific Software International, 1996
37 Kupek E. Bias and heteroscedastic memory error in self-reported health behavior: an investigation using covariance structure analysis. BMC Med Res Methodol 2002;2:14

38 Tuckman BW, Jensen MAC. Stages of small group development revisited. Group Organ Stud 1977;2:419-27

39 Crampton SM, Wagner JAI. Percept-percept inflation in microorganizational research: an investigation of prevalence and effect. J Appl Psychol 1994;79:67-76

40 Spector PE. Method variance as an artifact in self-reported affect and perceptions as work: myth or significant problem. J Appl Psychol 1987;72:438-43

41 Doty DH, Glick WH. Common methods bias: does common methods variance really bias results? Organ Res Methods 1998;1: 374-406

42 Maurer T, Weiss M, Barbeite F. A model of involvement in workrelated learning and development activity: the effects of individual, situational, motivational and age variables. J Appl Psychol 2003; 88:707-24 